\section{Can Older Gardeners Meet the Physical Activity Recommendation through Gardening?}

\author{
Sin-Ae Park ${ }^{1}$, Candice Shoemaker ${ }^{2,4}$, and Mark Haub ${ }^{2,3}$
}

AdDitional IndEx words. metabolic equivalents, Short-Form 36 Health Survey, indirect calorimetry, mental health, physical health

\begin{abstract}
SUMMARY. The objective of this study was to investigate if older gardeners meet the Centers for Disease Control and Prevention and American College of Sports Medicine physical activity (PA) recommendation of at least 30 minutes of moderate intensity PA on most days of the week through gardening. The heart rate of 14 gardeners (five women, nine men) aged 63 to 86 years was continuously measured through radiotelemetry, during gardening. Oxygen uptake and energy expenditure were measured through indirect calorimetry using a submaximal graded exercise test in a laboratory. To determine how long the subjects gardened and the kinds of gardening tasks performed, an observational study was conducted by two trained observers, and weekly logs were completed by the subjects. To investigate the subjects physical and mental health conditions, the Short-Form 36 Health Survey (SF-36) was used. Gardening was determined to be moderate intensity $(3.8 \pm 1.4$ metabolic equivalents) PA. The subjects' average gardening time during the observational study was 53 minutes. The subjects reported gardening an average of 33 hours in a typical week in May and almost 15 hours in a typical week in June and July. Results from the SF-36 indicated that the subjects were physically and mentally healthy. In conclusion, healthy older gardeners can meet the PA recommendation from their daily gardening and it may be a factor leading to good physical and mental health.
\end{abstract}

A bout $90 \%$ of adults over 65 years of age have at least one chronic health problem (Federal Interagency Forum on Aging Related Statistics, 2000; Hoffman et al., 1996). Biological changes, chronic diseases, functional disability, and psychological problems are common phenomena among the elderly (Dustman et al., 1994; Katz, 1983). Participation in regular physical activity (PA) may reduce and prevent many chronic diseases associated with aging and help maintain independent living (American College of Sports Medicine, 1998; Galloway and Jokl, 2000). The Centers for Disease Control and Prevention and the American College of Sports Medicine recommend at least 30 min of moderate intensity PA on most days of the week to maintain or improve health (Nelson et al., 2007; Pate et al., 1995). Moderate intensity PA, such as brisk walking, swimming, cycling, or dancing, causes some increase in breathing or heart rate (HR) (Marcus and Forsyth, 2003).

\footnotetext{
Kansas State University, 2021 Throckmorton Plant Science Center, Manhattan, KS 66506

${ }^{1}$ Department of Horticulture, Forestry, and Recreation Resources

${ }^{2}$ Center on Aging

${ }^{3}$ Department of Human Nutrition

${ }^{4}$ Corresponding author. E-mail: cshoemak@ksu.edu.
}

Gardening is a popular leisuretime activity (men $45 \%$, women $35 \%$ ) of adults aged 65 years or older in the United States (Yusuf et al., 1996). Gardening has the possibility of offering the health benefits from PA for older adults. Reynolds (1999) reported that gardening improved the grip strength of participants in a 6-month program, and cardiovascular fitness was expected because gardening activities elevated HR. In another study, Reynolds (2002) reported that participants in a 3-month gardening program showed improvement in mental health and depression. Gardening is expected to influence whole body bone mineral density because it includes weight-bearing motions such as pushing a mower, digging holes, pulling weeds, carrying soil and other gardening items, and because it uses the whole body (Turner et al., 2002). Turner et al. (2002) reported that jogging, swimming, and calisthenics were weak predictors for high bone density, while bicycling, aerobic exercise, walking, and dancing were moderate predictors, and yard work and weight training were strong and positive predictors. Although there is some evidence as to the positive health benefits from gardening, there is limited reported research on gardening for health in older populations.

Given the many health benefits of regular PA and that gardening is a major leisure-time activity of older adults, can gardening provide the health benefits of regular PA? In preliminary research, we determined that nine common gardening tasks were low to moderate intensity PA in older adults (S. Park, C. Shoemaker, and M. Haub, unpublished data). The HR of older adults, during nine common gardening tasks, was directly measured through radiotelemetry. After completion of the HR measurements, the subjects' oxygen uptake $\left(\mathrm{VO}_{2}\right)$ was measured through indirect calorimetry using a submaximal graded exercise test (GXT) in a laboratory. Based on the values of $\mathrm{HR}$ and $\mathrm{VO}_{2}$ from the gardening tasks, metabolic equivalents (METs) were calculated. METs are a common measure of exercise intensity - low intensity activities have a MET value of less than 3.0, moderate intensity have MET values of 3.0 to 6.0 , and vigorous intensity activity values are greater than 6.0 (Pate et al., 1995). Garden tasks that use the upper and lower body (digging, turning compost, raking, transplanting plants, and mulching) offered moderate intensity PA $(2.5 \pm 0.5$ to $3.6 \pm 0.8 \mathrm{METs}$ ) and tasks primarily using the upper body in a standing or squatting postures (hand weeding, mixing soil, filling containers with soil, and transplanting seedlings) were forms of low intensity PA $(1.6 \pm 0.5$ to $2.3 \pm 0.9$ METs). Therefore, our hypothesis for this study was that older adults who describe themselves as gardeners meet the PA recommendation

\begin{tabular}{llll}
\hline $\begin{array}{l}\text { Units } \\
\text { To convert U.S. to SI, } \\
\text { multiply by }\end{array}$ & U.S. unit & SI unit & $\begin{array}{l}\text { To convert SI to U.S., } \\
\text { multiply by }\end{array}$ \\
\hline 9.2303 & calorie $(\mathrm{s}) / \mathrm{lb}$ & $\mathrm{kJ} \cdot \mathrm{kg}^{-1}$ & 0.1083 \\
65.1985 & $\mathrm{fl} \mathrm{oz} / \mathrm{lb}$ & $\mathrm{mL} \cdot \mathrm{kg}^{-1}$ & 0.0153 \\
0.3048 & $\mathrm{ft}$ & $\mathrm{m}$ & 3.2808 \\
2.54 & inch $(\mathrm{es})$ & $\mathrm{cm}$ & 0.3937 \\
4.1868 & $\mathrm{kilocalorie}(\mathrm{s})$ & $\mathrm{MJ}$ & 0.2388 \\
0.4536 & $\mathrm{lb}$ & $\mathrm{kg}$ & 2.2046 \\
4.8824 & $\mathrm{lb} / \mathrm{ft}^{2}$ & $\mathrm{~kg} \cdot \mathrm{m}^{-2}$ & 0.2048 \\
$\left({ }^{\circ} \mathrm{F}-32\right) \div 1.8$ & ${ }^{\circ} \mathrm{F}$ & ${ }^{\circ} \mathrm{C}$ & $\left(1.8 \times{ }^{\circ} \mathrm{C}\right)+32$
\end{tabular}


(exercise intensity and time spent gardening) through their daily gardening. The hypothesis was tested using nonexperimental, descriptive methods of correlation, observation, and survey. This study is part of a larger investigation characterizing gardening activities to preserve physical function in older adults.

\section{Materials and methods}

SubJECTs. The list of volunteers that serve the Kansas State University Gardens was used to recruit participants by phone. Recruitment was also done in person at locations known to be frequented by older adults in Manhattan, KS, such as a senior center and coffee shops. Inclusion criteria were participants with no uncontrolled chronic diseases, no heart and lung diseases, no pacemaker, nonsmokers, and gardeners over 60 years old (while specific chronological markers for old age are arbitrary, gerontologists focus on aged 60 years and older, which is what we used in defining an older adult). Forty subjects were recruited and 14 met the criteria and obtained their physician's approval to participate. The 14 subjects were 63 to 86 years old, with five women and nine men. In an orientation session, informed written consent was obtained after the subjects were briefed on the experimental procedures and schedules. The study consisted of observing the subjects and measuring HR while they were gardening in their own garden, collecting metabolic measurements based on gardening HR in a laboratory, and completion of a survey and gardening logs. At the conclusion of the study, subjects received a \$10 gift card to a local market.

Observation. This study was conducted in Manhattan, KS, at each subject's garden in June and July 2006 in the morning or evening to avoid the hottest part of the day. Pretesting of the observational data sheet and training of the observers were done in Spring 2006. Two observers (a graduate student and an undergraduate student in the Department of Horticulture, Forestry, and Recreation Resources, Kansas State University) visited the subject's garden twice. The observational data sheet allowed the observers to easily record the gardening tasks observed and, using a stop watch, the time spent on each gardening task (Table 1). The data
Table 1. Recording sheet used by trained observers when observing older adults gardening in a study to determine if older gardeners meet the physical activity

recommendation of $30 \mathrm{~min}$ of moderate intensity physical activity most days of the week through their gardening activity. The

observational data sheet allowed the observers to easily record the gardening tasks observed and, using a stop watch, the time spent on each gardening task. This data sheet also included a section for the observers to record the body position performed and tools used during each gardening task (data not shown). In the example below, the person weeded for $30 \mathrm{~min}$, rested for $5 \mathrm{~min}$, and deadheaded for $10 \mathrm{~min}$. Instructions: Using the following table, write down each activity the gardener is performing and for how long throughout the entire observation time. Please explain how, as well as what, they are doing.

\begin{tabular}{|c|c|c|c|}
\hline $\begin{array}{l}\text { Gardening } \\
\text { activity }\end{array}$ & $\begin{array}{l}\text { How } \\
\text { long } \\
(\mathrm{min})\end{array}$ & Motion & $\begin{array}{l}\text { Tool } \\
\text { used }\end{array}$ \\
\hline Weeding & $30: 00$ & & \\
\hline Resting & 5:00 & & \\
\hline Deadheading & $10: 00$ & & \\
\hline
\end{tabular}

Total:

sheet also included a section for the observers to record the body positions used and the tools used during each gardening task (data not shown). The total amount of time spent gardening each time was recorded and there was no limitation by the observers on how long the subjects gardened or what gardening tasks they performed. The subjects performed their garden tasks freely without any limitation or interference from the observers. All subjects gardened no more than $2 \mathrm{~h}$ during the observations. The average temperature was $24.1^{\circ} \mathrm{C} \pm 3.3^{\circ} \mathrm{C}$ and the relative humidity was $67.1 \% \pm$ $21.8 \%$ during gardening.

Metabolic measurements. During the gardening observation, each subject's HR was continuously measured by radiotelemetry (Polar S 610i heart rate monitor; FitMed, Kempele, Finland). Each subject wore an HR monitor under their breast on the skin and had a wireless HR storage device on their wrist. The HR data were continuously recorded in the wireless storage from the start to the end of their gardening. After the two observational periods, each subject's $\mathrm{VO}_{2}$ was measured using a GXT in a laboratory setting. Each subject wore a mask over their mouth with their nose plugged and a HR monitor (Polar S 610i) under their breast while walking on a treadmill (model 964i; Precor, Woodinville, WA) at different speeds and elevations until reaching the highest $\mathrm{HR}$ that had been measured while they gardened (Gardening HRmax). Expired gases were directed to a metabolic cart (ParvoMedics, Provo, UT) through a nonrebreathing mouthpiece (HansRudolph, KS City). The flow meter and gas analyzers were calibrated before testing. Laboratory temperature and relative humidity were $26^{\circ} \mathrm{C}$ and $30 \%$ to $60 \%$, respectively.

The $\mathrm{HR}$ and $\mathrm{VO}_{2}$ measurements were used to calculate METs to determine the exercise intensity of gardening. One MET is a resting metabolic rate of $3.5 \mathrm{~mL} \cdot \mathrm{kg}^{-1} \cdot \mathrm{min}^{-1}$ oxygen. Energy expenditure (EE) and percentage of Gardening HRmax were calculated using the following equations:

$\mathrm{EE}$ in kilojoules per kilogram per hour

$=$ caloric expenditure in kilocalories per minute $\times(4.186 \times 60)$

$\div$ kilograms of body weight

Gardening HRmax in percent

$$
\begin{aligned}
& =\frac{\left(\text { Gardening } \mathrm{HR}_{\mathrm{AVG}}-\text { Resting HR }\right)}{(\text { Gardening HRmax }- \text { Resting HR })} \\
& \times 100
\end{aligned}
$$

Descriptive information on the subjects included height, weight, body mass index (BMI), resting $\mathrm{HR}$, and age-adjusted HRmax (age-adjusted HRmax $=220-$ age in years $)$. Height and weight were measured with a wall stadiometer (model 216 stadiometer; Seca, Brooklyn, NY) and electronic balance (model ES200L; Ohaus Corporation, Pine Brook, NJ), and BMI was calculated $[\mathrm{BMI}=$ weight in kilograms $\div$ (height in meters $)^{2}$ ]. Subjects sat on a chair before starting the GXT test and their resting HR data for $10 \mathrm{~min}$ was recorded.

Survey instrument. To determine the physical and mental health conditions of the subjects, the ShortForm 36 Health Survey (SF-36) was used. The SF-36 is a 36 -item self-rated 
survey that measures eight domains of health: physical functioning, role limitations due to physical health, bodily pain, general health perceptions, vitality, social functioning, role limitations due to emotional problems, and mental health. It yields scale scores for each of these eight health domains, and two summary measures of physical and mental health: the physical component summary and mental component summary. The SF-36 has proven useful in surveys of general and specific populations and in differentiating the health benefits produced by a wide range of different treatments. The reliability of the eight scales and two summary measures has been estimated using internal consistency and test-retest methods. Published reliability statistics have exceeded the minimum standard of the 0.70 recommended for measures used in group comparisons in more than 25 studies (Tsai et al., 1997); most have exceeded 0.80 (McHorney et al., 1994; Ware et al., 1993). Reliability estimates for physical and mental summary scores usually exceed 0.90 (Ware et al., 1994). Studies to date have reported content, concurrent, criterion, construct, and predictive evidence of validity (Ware, 2000).

At an orientation meeting, subjects completed the SF-36 survey and a questionnaire written by the researchers with demographic questions and questions on amount of time and frequency of each gardening task and the kinds of gardening they performed in May. Subjects were also given weekly logs to be completed twice, once during a typical week in June and again during a typical gardening week in July. The subjects were asked to record their gardening activities, time spent gardening, and the frequency of each task in their weekly logs. Time and frequency were used to calculate average gardening time.

Data Analysis. SF-36 data were scored using SF-36 Scoring Software (Quality Metric, Lincoln, RI). This software also performs norm-based scoring, through linear transformations of scores to a mean of 50 and standard deviations of 10 , in the general U.S. population. This transformation achieves the same mean and standard deviation for all eight scales and for the physical and mental summary measures. A norm-based score below 50 indicates that health-status is below average and above $\mathbf{5 0}$ indicates above average health status. With normbased scoring, differences in scale scores is more clearly reflected (Ware, 2000). Summary statistics were calculated using Excel (Microsoft Office 2002; Microsoft Corp., Redmond, WA).

\section{Results}

Characteristics of The SUBJECTS. The mean age of the subjects was $72 \pm 8$ years (Table 2 ). Fiftyseven percent of the subjects had home gardens, 29\% had a plot in a community garden, $7 \%$ had a garden at a space remote from their home, and $7 \%$ had a community garden and other space remote from their home.

SF-36 data indicated the subjects in this study were healthy. A comparison of SF-36 health determinates of the subjects and their age cohort from the general population based on the norm-based scoring indicated that the health conditions of the older gardeners in this study were above average, while that of their norm-based age cohort was below average (Table 3) (Ware, 2000; Ware et al., 2002).

OBSERVATION OF GARDENING. The gardeners in this study were found to be performing moderate intensity $(3.8 \pm 1.4 \mathrm{METs}) \mathrm{PA}$ and gardened on average $60 \pm 25 \mathrm{~min}$

Table 2. Descriptive characteristics of the subjects participating in the study to determine if older gardeners meet the physical activity recommendation of $\mathbf{3 0} \mathrm{min}$ of moderate intensity physical activity most days of the week through their gardening activities.

\begin{tabular}{|c|c|c|}
\hline \multirow[b]{2}{*}{ Measurement } & \multicolumn{2}{|c|}{$\begin{array}{l}\text { Subject } \\
(\mathrm{n}=14)\end{array}$} \\
\hline & Mean & SD \\
\hline Age (years) & 72 & 8 \\
\hline Race & White & \\
\hline Height $(\mathrm{cm})^{\mathrm{z}}$ & 168.9 & 7.0 \\
\hline Body wt $(\mathrm{kg})^{\mathrm{z}}$ & 80.1 & 14.0 \\
\hline $\begin{array}{l}\text { Body mass } \\
\quad \text { index }\left(\mathrm{kg} \cdot \mathrm{m}^{-2}\right)^{\mathrm{z}}\end{array}$ & 28.1 & 5 \\
\hline $\begin{array}{l}\text { Resting heart } \\
\text { rate (beats/min) }\end{array}$ & 76 & 9 \\
\hline $\begin{array}{l}\text { Resting metabolic } \\
\text { equivalents (METs) }\end{array}$ & 1 & 0.1 \\
\hline $\begin{array}{l}\text { Age-adjusted HRmax } \\
\text { (beats } / \min )^{y}\end{array}$ & 148 & 8 \\
\hline
\end{tabular}

Table 3. Average Short-Form 36 Health Survey (SF-36) scores for older adult subjects in a study to determine if older gardeners meet the physical activity

recommendation of $30 \mathrm{~min}$ of moderate intensity physical activity most days of the week through their gardening activity.

\begin{tabular}{|c|c|c|}
\hline SF-36 & $\operatorname{Avg}^{\mathrm{y}}$ & Standard $^{\mathrm{x}}$ \\
\hline Physical functioning & & \\
\hline Jsual role: $\mathrm{ph}$ & 50.69 & \\
\hline odily pain & & \\
\hline Teneral 1 & 54.83 & \\
\hline Vitality & 4.41 & \\
\hline ocial & 55.59 & \\
\hline $\begin{array}{r}\text { sual r } \\
\text { emot }\end{array}$ & 53.84 & 48.34 \\
\hline Mental health & 56.93 & \\
\hline $\begin{array}{l}\text { Physical health } \\
\text { summary }\end{array}$ & 51.04 & 43.93 \\
\hline $\begin{array}{l}\text { Iental health } \\
\text { summary }\end{array}$ & 56.68 & 51.57 \\
\hline \multicolumn{3}{|c|}{$\begin{array}{l}\text { } \mathrm{CSF}-36 \text { consists of eight scales and two summary } \\
\text { component measures (Ware et al., 1993). } \\
\text { "Norm-based scoring transformed to have a mean of } \\
50 \text { and an SD of } 10 \text { from the } 1998 \text { U.S. general } \\
\text { population. Health status is so it reads: A scale score } \\
\text { below } 50 \text { means health status is below average (Ware, } \\
2000 \text { ). } \\
\text { xThe values are norms for the general population aged } \\
65 \text { to } 74 \text { years old (Ware et al., 2002). }\end{array}$} \\
\hline
\end{tabular}

during a gardening observation (Table 4). The gardening tasks performed by more than $50 \%$ of the subjects are shown in Fig. 1.

SELF-REPORTED TIME SPENT AND TASKS PERFORMED WHILE GARDENING. The gardeners reported they spent an average of $33 \mathrm{~h}$ per week gardening in May. The garden tasks performed by more than $50 \%$ of older gardeners in May are shown in Fig. 2. The average time gardening in June and July was $15 \mathrm{~h}$ in $\mathrm{l}$ week. The garden tasks performed by more than $50 \%$ of the subjects during June and July are presented in Fig. 3.

\section{Discussion}

Can older gardeners meet the Centers for Disease Control and Prevention and the American College of Sports Medicine PA recommendation of at least $30 \mathrm{~min}$ of moderate intensity PA on most days of the week through gardening? Self-reported time spent gardening and metabolic measurements taken while gardening show that subjects performed at the intensity and time to meet the recommendation. The data from this study suggest that for 63 to 86-year-olds 
Table 4. Metabolic measurements of older adults from their gardening activities in a study to determine if older gardeners meet the physical activity recommendation of $\mathbf{3 0} \mathrm{min}$ of moderate intensity physical activity most days of the week through their gardening activity.

\begin{tabular}{lcc}
\hline & \multicolumn{2}{c}{$\begin{array}{c}\text { Subject } \\
(\mathbf{n}=\mathbf{1 4})\end{array}$} \\
\cline { 2 - 3 } Measurement & Mean & SD \\
\hline Gardening HR $_{\mathrm{AVG}^{\mathrm{z}}}$ & 98 & 18 \\
$\mathrm{VO}_{2}\left(\mathrm{~mL} \cdot \mathrm{kg}^{-1} \cdot \mathrm{min}^{-1}\right)^{\mathrm{y}}$ & 13.5 & 5.0 \\
\% Gardening HRmax & 49 & 21.9 \\
Gardening HRmax $^{\mathrm{w}}$ & 119 & 20 \\
Metabolic equivalents $^{\mathrm{v}}$ & 3.8 & 1.4 \\
Caloric expenditure & & \\
$\quad\left(\mathrm{kJ} \cdot \mathrm{kg} \cdot \mathrm{h}^{-1}\right)^{\mathrm{u}}$ & 17.1 & 9.3 \\
Gardening time $(\mathrm{min})$ & 60 & 25 \\
\hline
\end{tabular}

${ }^{\mathrm{z}}$ Gardening $\mathrm{HR}_{\mathrm{AVG}}=$ average heart rate measured continuously while gardening.

${ }^{y} \mathrm{VO}_{2}=$ average oxygen uptake measured using a submaximal graded exercise test in a laboratory based on gardening heart rate, $1 \mathrm{~mL} \cdot \mathrm{kg}^{-1} \cdot \mathrm{min}^{-1}=0.0153 \mathrm{fl}$ $\mathrm{oz} / \mathrm{lb}$ per minute.

xPercentage gardening $\mathrm{HRmax}=$ percentage of the highest gardening heart rate

"Gardening HRmax = highest heart rate measured while gardening.

Calculated using gardening heart rate and $\mathrm{VO}_{2}$.

"l $\mathrm{kJ} \cdot \mathrm{kg} \cdot \mathrm{h}^{-1}=0.1083$ calorie $/ \mathrm{lb}$ per hour.

that identify themselves as gardeners, gardening can contribute to the 30 min per day of moderate intensity activity required to confer health benefits during the months of May, June, and July in middle America.

In this study, the gardening tasks performed by more than $50 \%$ of the older gardeners while being observed gardening and reported in their gardening logs overlapped considerably. Even though the subjects $\mathrm{HR}$ was measured while gardening only on $2 \mathrm{~d}$, this considerable overlap in observed and self-reported garden tasks suggests that the exercise intensity of their daily gardening activities can be considered as a moderate intensity PA.

Gardening in May included two different tasks, trimming and planting seedlings or shrubs, compared with gardening tasks performed in June and July. This variation of tasks indicates that gardening is a dynamic activity because the garden tasks change with the seasons and the various plant growth cycles. Boredom during exercise is commonly cited as a reason for not exercising (Restuccio, 1992); however, because gardening tasks provide interest and change throughout the seasons, it may foster

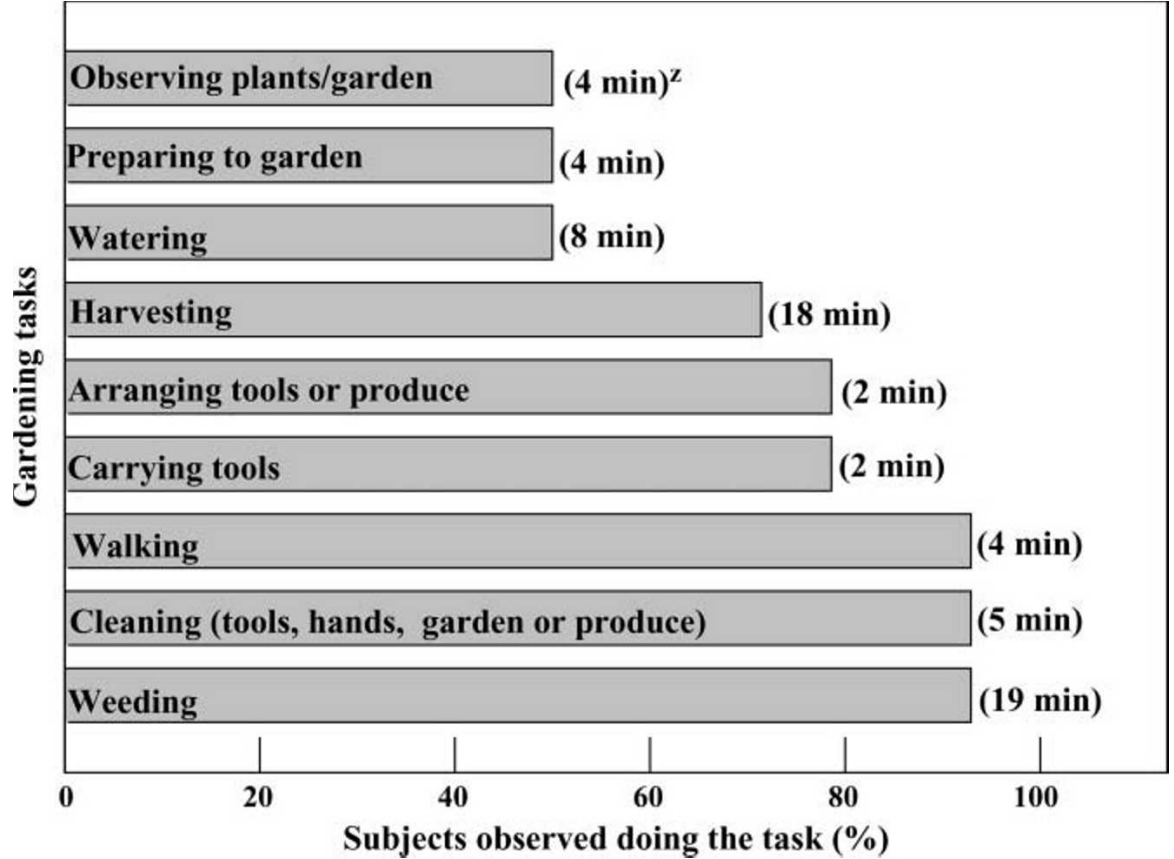

Fig. 1. Gardening tasks performed by more than $\mathbf{5 0 \%}$ of subjects that were observed gardening in June and July in a study to determine if older gardeners meet the physical activity recommendation of $\mathbf{3 0}$ min of moderate intensity physical activity most days of the week through their gardening activity. ${ }^{\mathrm{z}}$ Average time of the gardening task reported in parentheses.

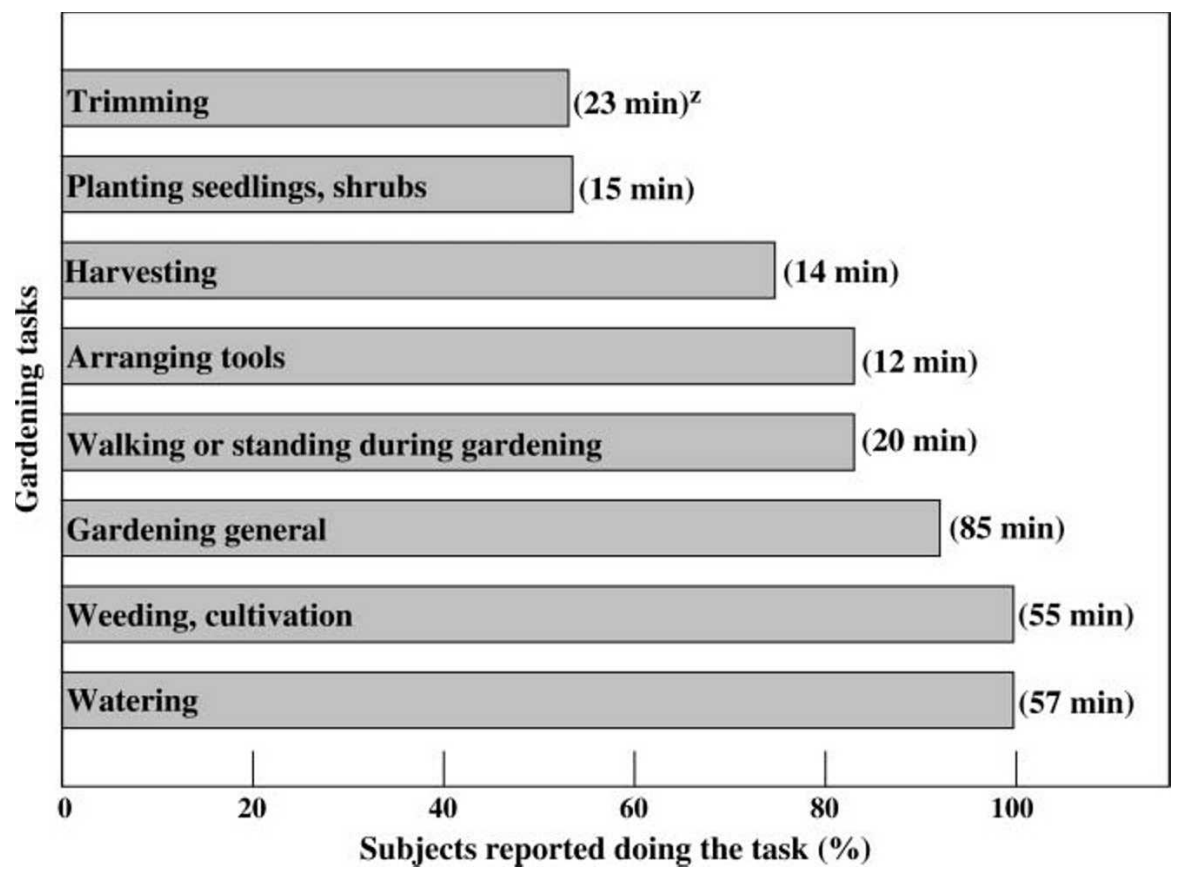

Fig. 2. Gardening tasks performed by more than $\mathbf{5 0 \%}$ of subjects in May from a written questionnaire in a study to determine if older gardeners meet the physical activity recommendation of 30 min of moderate intensity physical activity most days of the week through their gardening activity. ${ }^{\mathrm{z}}$ Average time of the gardening task reported in parentheses.

PA. A sedentary lifestyle is one of the factors for increased risk in the decline of functional status of muscular strength and endurance, flexibility, balance, and cardiopulmonary capacity, particularly in older adults (Burbank and Riebe, 2002). Gardening encourages activity, thus helping to avoid a 


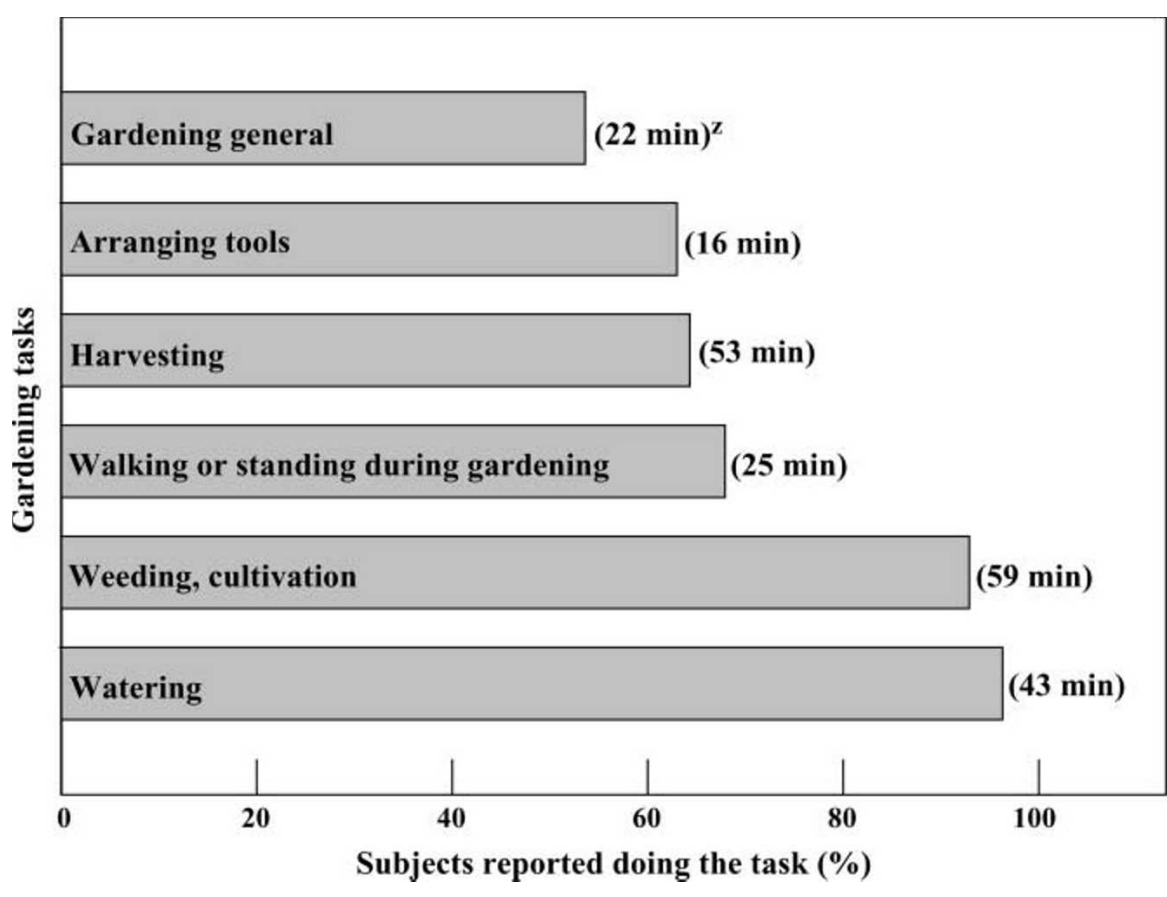

Fig. 3. Gardening tasks performed by more than $50 \%$ of subjects in June and July as reported in their weekly logs in a study to determine if older gardeners meet the physical activity recommendation of $\mathbf{3 0} \mathrm{min}$ of moderate intensity physical activity most days of the week through their gardening activity. ${ }^{\mathrm{z}}$ Average time of the gardening task reported in parentheses.

sedentary lifestyle. On the other hand, the seasonality of gardening can be a limiting factor or limitation for regular PA. Mobily et al. (1995) reported that gardening and yard work activities were restricted to seasonal variations. For example, older adults in two medium-sized midwestern U.S. communities spent $\approx 57 \mathrm{~min}$ gardening and $506 \mathrm{~min}$ in yard work in the winter season.

Results from this study support the need for a larger similar study that would encompass all the regions of the United States. Continued research in this area should investigate the specific effects of gardening on health issues in older adults.

\section{Literature cited}

American College of Sports Medicine. 1998. Exercise and physical activity for older adults. Med. Sci. Sports Exerc. 30:992-1008.

Burbank, P.M. and D. Riebe. 2002. Promoting exercise and behavior change in older adults: Interventions with the transtheoretical model. Springer, New York.

Dustman, R.E., R. Emmerson, and D. Shearer. 1994. Physical activity, age, and cognitive-neuropsychological function. J. Aging Phys. Act. 2:143-181.
Federal Interagency Forum on Aging Related Statistics. 2000. Older American 2000: Key indicators of well-being. Federal Interagency Forum on Aging Related Statistics, Washington, DC.

Galloway, M.T. and P. Jokl. 2000. Aging successfully: The importance of physical activity in maintaining health and function. J. Amer. Acad. Orthop. Surg. 8:37-44.

Hoffman, C., D. Rice, and H.Y. Sung. 1996. Persons with chronic conditions: Their prevalence and costs. J. Amer. Medical Assn. 276:1473-1479.

Katz, S. 1983. Assessing self-maintenance: Activities of daily living, mobility and instrumental activities of daily living. J. Amer. Geriatr. Soc. 31:721-727.

Marcus, B.H. and L.H. Forsyth. 2003. Description of physical activity interventions, p. 4-5. In: Motivating people to be physically active. Human Kinetics, Champaign, IL.

McHorney, C.A., J.E. Ware, J.F.R. Lu, and C.D. Sherbourne. 1994. The MOS 36-item short-form health survey (SF$\left.36^{\circledR}\right)$ : III. Tests of data quality, scaling assumptions and reliability across diverse patient groups. Med. Care 32(4):40-66.

Mobily, K.E., R. Nilson, L.J. Ostiguy, R.D. MacNeil, and R.B. Wallace. 1995. Seasonal variation in physical activity in older adults. Top. Geriatric Rehab. 10(3): 11-22.
Nelson, M.E., W.J. Rejeski, S.N. Blair, P.W. Duncan, J.O. Judge, A.C. King, C.A. Macera, and C. Castaneda-Sceppa. 2007. Physical activity and public health in older adults: Recommendation from the American College of Sports Medicine and the American Heart Association. Med. Sci. Sports Exerc. 39(8):1435-1445.

Pate, R.R., M. Pratt, S.N. Blair, W.L. Haskell, C.A. Macera, C. Bouchard, D. Buchner, W. Ettinger, G.W. Heath, A.C. King, A. Kriska, A.S. Leon, B.H. Marcus, J. Morris, R.S. Paffenbarger, K. Patrick, M.L. Pollock, J.M. Rippe, J. Sallis, and J.H. Wilmore. 1995. A recommendation from the Centers for Disease Control and Prevention and the American College of Sports Medicine. J. Amer. Medical Assn. 273:402-407.

Restuccio, J.P. 1992. Fitness the dynamic gardening way. Balance of Nature, Cordo, TN.

Reynolds, V. 1999. The Green Gym: An evaluation of a pilot project in Sonning Common, Oxfordshire. Report no. 8. Oxford Brookes Univ., Oxford, UK.

Reynolds, V. 2002. Well-being comes naturally: An evaluation of the BTCV Green Gym at Portslade, East Sussex. Report no. 17. Oxford Brookes Univ., Oxford, UK.

Tsai, C., M.S. Bayliss, and J.E. Ware. 1997. SF-36 ${ }^{\circledR}$ health survey annotated bibliography: Second edition (19881996). Health Assessment Laboratory, New England Medical Center, Boston.

Turner, L.W., M.A. Bass, L. Ting, and B. Brown. 2002. Influence of yard work and weight training on bone mineral density among older U.S. women. J. Women Aging 14:139-149.

Ware, J.E. 2000. SF-36 health survey update. Spine 25(24):3130-3139.

Ware, J.E., M. Kosinski, and S.K. Keller. 1994. SF-36 ${ }^{\circledR}$ physical and mental health summary scales: A user's manual. Health Institute, New England Medical Center, Boston.

Ware, J.E., M. Kosinski, D.M. TurnerBowker, and B. Gandek. 2002. How to score version 2 of the SF-12 health survey. QualityMetric Inc., Lincoln, RI, and Health Assessment Laboratory, Boston.

Ware, J.E., K.K. Snow, M. Kosinski, and B. Gandek. 1993. SF-36 health survey: Manual and interpretation guide. Health Institute, New England Medical Center, Boston.

Yusuf, H.R., J.B. Croft, W.H. Giles, R.F. Anda, M.L. Casper, C.J. Caspersen, and D.A. Jones. 1996. Leisure-time physical activity among older adults: United States. Arch. Intern. Med. 156:1321-1326. 